\title{
A AUTONOMIA DA ESCOLA NA PERSPECTIVA DA GESTÃO DEMOCRÁTICA: ENTRE O PREPOSTO E O EXISTENTE NO INTERIOR DE UMA ESCOLA PÚBLICA DE BELO HORIZONTE/MG ${ }^{1}$
}

http://dx.doi.org/10.5902/2318133833782

\author{
José Márcio Silva Barbosa² \\ Fernando Alvarenga Cardoso Coelho ${ }^{3}$
}

\begin{abstract}
Resumo
Neste texto tem-se como objetivo compreender até que ponto a autonomia da escola pode contribuir para o enfrentamento das situações concretas relativas à gestão da escola pública ultrapassando o discurso generalizante que termina por constituir contemplativamente na construção da gestão democrática. Utilizou-se como procedimento metodológico a pesquisa qualitativa de cunho bibliográfica, análise documental e estudo de caso, utilizando para coleta de dados entrevista semiestruturada aplicada a um gestor de escola pública da rede estadual de ensino. Fortalecer o compromisso do gestor escolar e de professores para a construção da gestão democrática e para autonomia nuclear nas tomadas de decisões da escola continua a ser um bom caminho a percorrer.
\end{abstract}

Palavras-chave: autonomia da escola; gestão democrática; práticas de gestão escolar.

\section{THE AUTONOMY OF THE SCHOOL IN THE PERSPECTIVE OF DEMOCRATIC MANAGEMENT: BETWEEN THE PREPOSTO AND THE EXISTING ONE INSIDE A PUBLIC SCHOOL OF BELO HORIZONTE/MG}

Abstract

This article aims to understand the extent to which the autonomy of the school has contributed to the confrontation of the concrete situations related to the management of the public school, surpassing the generalizing discourse that ends up constituting itself in the construction of democratic management. As a methodological procedure, we used qualitative bibliographic research, documentary analysis and case study, employing semi-structured interview data collection. The interview was made to a state public school manager. Strengthening the commitment of the school manager and teachers in the construction of democratic management and for nuclear autonomy in school decision making is still a good way to go.

Key-words: autonomy of the school; democratic management; school management practices.

\footnotetext{
1 Este projeto contou com financiamento institucional do Programa Institucional de Apoio à Pesquisa da Universidade do Estado de Minas Gerais, Faculdade de Educação, campus de Belo Horizonte.

2 Universidade do Estado de Minas Gerais, Brasil. E-mail: imarciosb@yahoo.com.br.

3 Universidade do Estado de Minas Gerais, Brasil. E-mail: fernando-alvarenga@live.com.

\begin{tabular}{|l|l|l|l|l} 
Regae: Rev. Gest. Aval. Educ. & Santa Maria & v. 8 & n. 17 & Pub. contínua 2019
\end{tabular} 


\section{Introdução}

presente texto constitui-se em resultado de uma pesquisa elaborada sobre a autonomia da escola na perspectiva da gestão democrática: entre o preposto e o existente no interior de uma escola pública de Belo Horizonte/MG, desenvolvida na Faculdade de Educação da Universidade do Estado de Minas Gerais.

O objetivo central da pesquisa foi compreender e descrever as práticas decorrentes das decisões do gestor uma escola pública da rede estadual de Belo Horizonte/MG, previamente tomadas e referenciadas por medidas mais autônomas e na perspectiva da construção de uma gestão mais democrática no âmbito escolar.

Especificamente, pretendeu-se delimitar o referencial teórico que aborda a autonomia da escola e os princípios de gestão democrática que reporta a busca de conhecimento e fundamentação teórica, bem como atribuições à gestão escolar; investigar documentos oficiais da legislação brasileira o que tem sido preposto de forma a tornar a gestão das escolas mais democráticas e autônomas, bem como a orientar a tomada de decisões desejáveis ao gestor escolar para suas realizações; bem como verificar o que tem de existente no trabalho cotidiano do gestor escolar e nas práticas escolares, bem como os instrumentos necessários que repercutem na construção da gestão democrática e da autonomia pedagógica e administrativa no contexto escolar.

Acentua-se uma compreensão de fato que neste espaço possam se desenrolar diversas situações que se forem levadas a gerar interpretações, sem desconsiderar a realidade de cada sistema de ensino e de cada unidade escolar, sempre trazem um potencial de fazer acontecer, de direcionar ações, de induzir transformações, quaisquer que sejam as efetivas práticas de gestão realizada no contexto escolar.

A valoração da atuação do gestor escolar, paralela a concretização destas medidas, acaba por atribuí-lhe responsabilidades quase total pelo destino da escola, já que ele é considerado o responsável último das decisões tomadas pela equipe escolar, à medida que as vertentes teóricas educacionais apontam a autonomia da escola na perspectiva de gestão democrática como um novo modo de gerir a escola e nascem daí as perspectivas de uma democratização da escola brasileira, fundamentado em ações concretas no interior da gestão escolar.

A construção da autonomia da escola na perspectiva da gestão democrática passa a ser uma necessidade e um desafio para o sistema de ensino. Assim, o presente trabalho visa a contribuir para o debate a respeito da atuação do gestor escolar, por que possa identificar, questionar e refletir sobre as fragilidades percebidas no encaminhamento e execução de determinada ação pedagógica para construção de sua autonomia escolar.

\section{A autonomia da escola e gestão democrática}

Sabe-se que o termo autonomia é indispensável às necessidades da escola, bem como deverá ser um processo que procura democratizar a prática pedagógica, atividades e projetos a serem desenvolvidos pelos profissionais da educação. Ao orientar suas práticas para o fortalecimento de sua própria autonomia, a escola pode constituir-se do princípio básico e norteador para a efetiva atuação do gestor escolar para a construção da 
gestão democrática da escola. Entendemos que, por meio da autonomia da escola, permite-se criar condições para mudanças que direcionam a comunidade escolar aos seus problemas e potencialidades, contando com uma nova atitude da gestão da escola, que possibilite uma melhor resposta aos desafios da mudança.

Nesse sentido, reconhece-se a importância da participação efetiva e consciente de todos aqueles que compõem o esqueleto da organização escolar. Por isso, pesquisar as questões referentes à gestão escolar no processo de implantação de políticas educacionais requer a observação da intepretação que os atores sociais - diretor e professor, aluno, pais, membros da comunidade - fazem sobre os fatos ou propostas expostas. Estudos mostram que a autonomia, neste contexto, se constitui um princípio de gestão quando oportuniza a participação na tomada de decisões, fomentando a avaliação dos resultados e direcionando o olhar de todos os atores envolvidos nesse processo para o planejamento das ações, atividades e projetos a serem desenvolvidos pela escola. É possível apreender algumas características que hoje se fazem presentes nos procedimentos adotados na gestão de escolas públicas.

Desse modo, reconhece-se a importância da autonomia para o funcionamento da escola, o que reforça a ideia de que a autonomia pressupõe o reconhecimento, mediante certas condições, em gerir melhor os recursos educativos de forma consistente com o seu projeto pedagógico. Logo, a autonomia escolar deve tornar o fator orientador da atuação do gestor escolar, uma vez que há uma grande diversidade de demandas educativas a serem contempladas na escola. Entre as medidas que se procuram desenvolver na escola destacam-se a autonomia pedagógica, administrativa, financeira e política, desde que a cada uma dela seja possível e assegurada de modo que suas ações e iniciativas contemplem uma tentativa de democracia participativa na escola.

Para Lück (2000) merece ser destacada a dimensão política, uma vez que ela se refere à capacidade de tomar decisões compartilhadas e comprometidas, sem as quais as demais dimensões não se efetivam. No exercício da dimensão política da autonomia, o gestor deve usar talento e competência para articular e organizar, de forma conjunta com a comunidade escolar, a solução dos problemas e dos desafios educacionais.

Machado e Miranda (2012) defendem a ideia de que sendo a autonomia um meio e não um fim em si mesmo, a dimensão política irá garantir o exercício financeiro e administrativo, cujo objetivo é assegurar a autonomia pedagógica, dimensão na qual a escola realiza as adequações das diretrizes curriculares, de acordo com as suas especificidades locais. Isto nos leva a crer que a autonomia da escola não se constrói isoladamente. Portanto, é imprescindível a participação coletiva da equipe escolar nas tomadas de decisões e para a execução de suas atividades escolares, ou seja, "a autonomia se faz pelo exercício de articulação da comunidade escolar, juntamente com a clareza das relações de interdependência que se estabelecem entre a escola e as suas instâncias superiores" (p. 11).

Porém, o processo de gestão democrática traz em suas bases políticas a descentralização visando à constituição da autonomia escolar. Neste sentido, ação democrática é exercício de poder, autocriação, auto-instituição, autogestão. Gestão democrática se constrói no cotidiano escolar, no espaço do exercício da autonomia, instituída pela vontade e segundo os valores e objetivos coletivos. Para que a gestão da 
escola pública seja efetivamente democrática é fundamental que ela tenha seu espaço de autonomia, inclusive para decidir que tipo de exercício democrático deseja praticar (Brasil, MEC, 2014).

Segundo Machado e Miranda (2012) as razões que levam as organizações a adotarem estruturas mais descentralizadas estão relacionadas ao crescente dinamismo do ambiente em que operam. O bom desempenho de uma organização depende cada vez mais da sua capacidade de adaptação às mudanças impostas por esse ambiente. Quanto mais dinâmico for o ambiente, maior a necessidade de flexibilidade e maior a capacidade de adaptação que a organização terá. Podemos afirmar que a descentralização propicia essa flexibilidade na medida em que permite que as decisões sejam tomadas em nível local, ou seja, por aqueles que melhor conhecem as atividades, as particularidades e a realidade da organização.

Ao orientar suas práticas para o fortalecimento de sua própria autonomia, a escola pode construir o seu conceito de qualidade de ensino e adequar melhor a sua função às necessidades da comunidade. $O$ projeto político-pedagógico constitui, concomitantemente, um direito e um dever da escola por se tratar de um documento que norteia e sistematiza o trabalho, ao mesmo tempo em que consolida a autonomia da escola, quando dá abertura para o processo de ação-reflexão-ação, mediante ao planejamento realizado coletivamente.

Deve-se salientar que o PPP é um documento que reproduz as intenções da equipe escolar, bem como nas formas de organização e de gestão escolar. Para Machado e Miranda (2012) o PPP deve abranger a política educacional da escola, suas normas e regulamentos, a partir da definição do cenário e do seu contexto de atuação, do conhecimento dos seus pontos fortes e fracos e das metas pactuadas que irão garantir a efetivação das diretrizes e políticas definidas em nível macro do sistema educacional.

Neste sentido, a construção do PPP traz à tona questões exigidas à gestão escolar englobando as questões administrativas, pedagógicas e financeiras, construído a partir da participação de todos os que compõem a comunidade escolar. Dito de outro modo, a autonomia da escola se reveste na liberdade que a comunidade escolar tem em elaborar PPP cuja participação, reponsabilidade e colaboração nas tomadas de decisões entre todos envolvidos com o processo de escolarização ganha relevo e significa valorizar as ações concretas dos profissionais da escola que sejam decorrentes de sua iniciativa, de seus interesses, de suas interações e do envolvimento de todos os responsáveis pela construção da prática concreta da educação.

A autonomia da escola e a democratização de sua gestão demandam re-construção teórico-prática, o que se constitui uma reinvenção de educação. Para o autor, os avanços no pensar e fazer da educação vem demonstrando que todos podem aprender e que a construção de um processo educativo de qualidade para todos e isto implica a construção co-responsável e compartilhado do projeto político-pedagógico, no âmbito escolar (Machado; Miranda, 2012). Seguindo as instruções do autor, a centralidade da escola e de democratização da educação visando atender exigências pedagógicas já está expressa em dispositivos legais, que determinam a responsabilidade da administração publica em assegurar progressivos graus de autonomia e gestão democrática às escolas. Desse modo, cabe ao diretor escolar enquanto líder e responsável pela tomada de decisões na escola, propiciar a busca pela realização de um trabalho pedagógico coletivo. 
Ainda no que concerne à figura do diretor, trata-se de se questionar a atual situação em que este acaba se constituindo em mero preposto do Estado na escola, cuidando para o cumprimento da lei e da ordem ou da vontade do governo no poder, como afirma Paro (2015).

Como já salientamos anteriormente, a noção central é aqui a de que a autonomia escolar como elemento construtor da gestão democrática. Nesse processo, o gestor escolar se destaca como líder e responsável em construir uma gestão democrática na escola através de autonomia pedagógica, administrativa e financeira. É fundamental que ele tenha seu espaço de autonomia, inclusive para decidir que tipo de exercício democrático deseja praticar. Para garantir o espaço de autonomia da escola é preciso que a lei da gestão democrática afirme como diretrizes e princípios, bem como estratégias do alcance dos objetivos legais. Garantidos os princípios, a norma deve ser sucinta o suficiente para não invadir rotinas e práticas do cotidiano escolar e padronizar o diferente, matando no nascedouro a possibilidade de singulares e ricas experiências. Nesse sentido É importante que a escola possa regulamentar em seu regimento normas relativas a seu conselho e buscar a construção de gestão mais democrática que concebe e deseja praticar (Brasil, 2004).

A partir destas considerações apontadas, Paro (2015) afirma que "são as razões técnico-administrativas (adequação entre meios e fins) que nos convencem da necessidade do caráter dialógico-democrático (convivência entre sujeitos que as afirmam como tais) das relações que se dão nos processos pedagógicos, o qual determina e é determinada pela ação do diretor" (p. 109).

O foco principal das discussões mais recentes tem sido a questão do papel do gestor escolar com ênfase no projeto político-pedagógico. A utilização deste instrumento no ambiente escolar tem sido visto como possível alcance da a necessidade de autonomia para que a gestão da escola ocorra de forma democrática e participativa, envolvendo, desse modo, práticas que buscam soluções próprias para seus problemas e, portanto, mais adequadas às suas necessidades.

A essência da gestão democrática é o espaço de autonomia. A gestão democrática é o exercício de poder, autocriação e autogestão. Ela se constitui, no cotidiano escolar, no espaço do algumas questões para discussão. Sendo assim, o exercício da autonomia instituída pela vontade e segundo os valores e objetivos coletivos da escola, torna-se o caminho necessário e urgente para a escola pública seja efetivamente democrática (Brasil, 2004).

Embora se reconheça a importância da construção de processos de gestão democrática e da autonomia das escolas nos sistemas de ensino, é necessário que seus gestores possuam uma atuação que revele práticas democráticas e autônomas, uma vez que são sujeitos fundamentais para que esse processo se desencadeie e se efetive.

Para Libâneo, Ferreira e Toschi (2010) esses processo de chegar a uma decisão e de fazer a decisão funcionar caracterizam a ação designada como gestão, onde a direção põe em ação o processo de tomada de decisões na organização e coordena trabalhos, de modo que sejam realizados da melhor maneira possível. Pela peculiaridade democrática e 
pública de sua função o dirigente escolar precisar ser democrático no sentido pleno desse conceito, ou seja, sua legitimidade advém essencialmente da vontade livre e do consentimento daqueles que se submetem a sua direção (Paro, 2015).

Ainda que tenha sido uma experiência positiva, há necessidade de compreender a escola como espaço de construção democrática, respeitando o caráter autônomo que se estruturam nas unidades escolares e que se orientem para fazer da escola um centro educativo participativo, democrático e qualitativo comtemplados em sua plenitude.

\section{O proposto na legislação brasileira}

A constituição Federal de 1988 propõe a gestão democrática da escola pública como ícone de uma nova compreensão em torno da educação e das relações no interior da escola. Após esta legislação brasileira, à medida que os sistemas de ensino se estruturaram e se fortaleceram, houve a necessidade de progressiva ampliação do espaço de autonomia da escola, que agora vigorosamente se deseja retomar, fator gerador de tensões no exercício de poder (Brasil, 2014).

A autonomia passou a se constituir a palavra de ordem para a construção de uma escola efetivamente democrática e vem assumindo grande centralidade no âmbito das discussões educacionais.

A unidade escolar democrática tem sua gestão amparada no trabalho coordenado de todos os agentes envolvidos no processo educacional. O entendimento da relevância da inclusão comunitária na percepção coletiva do processo educacional dos instrumentos de construção desse processo potencializam a difusão do sentimento de pertencimento e integração entre escola e comunidade. $O$ reforço desse laço revigora o sentimento de partilha, tornando o processo vivo e dinâmico e caracterizando pragmaticamente o caráter democrático da interação estabelecida. A adoção de uma nova visão para os processos resulta consequentemente na mudança de atitude necessária ao desenvolvimento de uma nova postura ante a questão da escola (Brasil, 2014).

O fundamento da gestão democrática situa o poder de decisão na estrutura de gestão da escola. Situá-lo fora daí equivaleria a privar a escola de autonomia, arrancarIhe a essência da gestão democrática, da pedagogia cidadã. Se colocarmos ao lado ou sobre a escola outra entidade com poder deliberativo sobre ela, mesmo que constituída pelas categorias integrantes da própria escola, estaremos negando o que queremos afirmar, ou seja: despojando a escola de sua autonomia, de sua essencialidade educativa, cidadã.

Em decorrência da promulgação da Lei de Diretrizes e Base da Educação Nacional de 1996, há a previsão de uma adequação às especificidades no contexto escolar, colocando-a como um dos pilares central. Desse modo, a autonomia da escola em sendo assegurada no artigo 15ำ da LDB: "Os sistemas de ensino assegurarão às unidades escolares públicas de educação básica que os integram progressivos graus de autonomia pedagógica e administrativa e de gestão financeira, observadas as normas gerais de direito financeiro público. (Brasil, 1996).

De acordo com a LDB a autonomia da escola possui três dimensões: pedagógica, administrativa e financeira. A descentralização possui um papel fundamental na construção da autonomia da escola, assim, 
a descentralização é um meio e não um fim, na construção da autonomia, assim como esta, é, também, um meio para a formação democrática dos alunos. [...] a autonomia, no contexto da educação, consiste na ampliação do espaço de decisão, voltada para o fortalecimento da escola como organização social comprometida reciprocamente com a sociedade, tendo como objetivo a melhoria da qualidade do ensino. Autonomia é a característica de um processo de gestão participativa que se expressa, quando se assume com competência a responsabilidade social de promover a formação de jovens adequada às demandas de uma sociedade democrática em desenvolvimento, mediante aprendizagens significativas. (Lück, 2000, p. 21)

A questão da autonomia remete à questão da institucionalidade que reveste a escola de personalidade, identidade própria. As unidades federadas, no exercício de sua autonomia para definir as normas de seus sistemas de ensino, parecem estar diante de um impasse para conciliar dois princípios legais coerentes e indissociáveis: o constitucional, da gestão democrática da educação pública, e o da LDB, da progressiva autonomia da escola pública (Brasil, 2014).

Dessa forma, compreendem-se a autonomia e a descentralização como aspectos característicos da gestão democrática e que não podem ser entendidos de maneira dissociada. A descentralização das decisões contribui de maneira significativa para a construção da autonomia da escola e esta constitui um aspecto fundamental da gestão democrática, o que segundo Paro (2001) "a descentralização do poder se dá na medida em que se possibilita cada vez mais aos destinatários do serviço público sua participação efetiva, por si ou por seus representantes, nas tomadas de decisão" (p. 57). A partir dessa constatação, a questão central em torno da autonomia da escola parece residir nas possiblidades em que ela possa ampliar os seus espaços de iniciativa no poder de decisão. Embora o tema seja relevante tanto por parte das intenções politicas quanto às análises da gestão escolar, estamos partindo da hipótese, que pouco se tem investigado a respeito de sua efetiva consolidação no sistema de ensino.

Para garantir o espaço de autonomia da escola é preciso que o princípio da gestão democrática afirme diretrizes e princípios, como estratégias do alcance dos objetivos legais. Garantidos os princípios, a norma deve ser sucinta o suficiente para não invadir rotinas e práticas do cotidiano escolar e padronizar o diferente, matando no nascedouro a possibilidade de singulares e ricas experiências. Nesse sentido é importante que a escola possa regulamentar em seu regimento normas relativas a seu conselho e à gestão democrática que concebe e deseja praticar (Brasil, 2014).

Desse modo, cabe a cada unidade escolar, segundo Machado e Miranda (2012), ter autonomia para adequar as diretrizes e políticas provenientes das instâncias superiores do sistema educacional à sua realidade local, não podendo ser traduzida de modo isolado, sem levar em conta outros domínios das políticas educacionais, tendo em vista que o desdobramento de políticas de autonomia e de responsabilização em práticas de gestão e em resultados efetivos depende de uma compreensão clara do significado de gestão educacional e das principais características dos sistemas de educação.

Portanto, pode-se afirmar que não há autonomia sem a capacidade de assumir responsabilidades, ou seja, a escola deve responder por suas ações, prestar contas dos seus atos e realizar os seus compromissos, de modo a enfrentar reveses e dificuldades

\begin{tabular}{|l|l|l|l|l|r|} 
Regae: Rev. Gest. Aval. Educ. & Santa Maria & v. 8 & n. 17 & Pub. contínua 2019 & p. 1-15
\end{tabular}


como afirma Lück (2000). Por outro lado, considerando uma perspectiva integrada de gestão, modificam-se os papéis e as responsabilidades tanto da equipe gestora quanto da comunidade escolar. Cabe aos gestores das escolas a mudança de postura para assumirem comportamentos mais proativos, deixando de ser sujeitos passivos no sistema. Desse modo, a possibilidade de melhor desempenho da escola, em termos de qualidade e alcance de metas, depende de um melhor desempenho da sua gestão. (Machado; Miranda, 2014). Assumindo que, nesses discursos, encontram-se expressas ideias que tentam responder sobre o que se expressa entre o sistema de ensino e no seu interior, é preciso oferecer descrições amplas do que tem sido desenvolvido e atingido na gestão escolar.

\section{O existente no interior de uma escola pública}

Por meio da discussão bibliográfica entendemos que a existência da autonomia escolar para a construção da gestão democrática da escola é necessária e urgente. Para intensificar esta relação é necessária que compreendamos o que há de existente no interior da escola pública ou pelo menos, o que sugerem educadores e pesquisadores acadêmicos que se fomentará a ação do gestor escolar. Para tanto, recorremos a autores, num diálogo que favorece a interação de ideias e debates, procurando alinhavar os pontos comuns e complementares entre eles.

Para Machado e Miranda (2014) a gestão escolar assume papel determinante, uma vez que cabe ao gestor a função de liderança: ele deve articular os diversos segmentos da escola, atuando como mediador no processo de construção das ações empreendidas pela comunidade escolar, no sentido de que a proposta da escola esteja em acordo com a do sistema, ou seja, as escolas não funcionam de forma isolada da rede e, por conseguinte, a sua gestão precisa, necessariamente, considerar o desdobramento de diretrizes, políticas e regulamentações na busca por melhores resultados educacionais.

Nesta perspectiva, a escola se faz democrática, de fato garantindo a participação de todos, através de sua gestão e por um documento denominado Projeto políticopedagógico. É pensar sobre a prática implica buscar alternativas para mudanças, tomar decisões para a inovação da prática educacional (Dalberto, 2009).

Assim, o desdobramento de políticas de autonomia e de responsabilização em práticas de gestão e em resultados efetivos depende de uma compreensão clara do significado de gestão educacional e das principais características dos sistemas de educação. (Machado; Miranda, 2014). Para Dalberto (2009) estamos diante de um impasse e de um grande desafio: "Construir uma escola de qualidade que possa, de fato, cumprir sua função e abrir caminhos para uma sociedade mais harmoniosa e inclusiva" ( $p$. 91). Por outro lado, considerando uma perspectiva integrada de gestão, modificam-se os papéis e as responsabilidades tanto da equipe gestora quanto da comunidade escolar. Cabe aos gestores das escolas a mudança de postura para assumirem comportamentos mais proativos, deixando de serem sujeitos passivos no sistema. Desse modo, a possibilidade de melhor desempenho da escola, em termos de qualidade e alcance de metas, depende de um melhor desempenho da sua gestão.

Neste processo assumem especial importância os dirigentes dos sistemas de ensino precisam nutrir sua ação nos fundamentos da efetiva gestão democrática do ensino público, para disseminar nas escolas a cultura democrática. Enquanto não superarmos a 
cultura patrimonialista, que gera atitudes de donos do poder, ou do saber, não florescerá nas escolas o hábitat adequado para o efetivo exercício da gestão democrática, fundamento da cidadania (Brasil, 2014).

Tendo em vista que é da ação concreta deste profissional diretamente envolvido com a gestão da escola que se constrói a autonomia. Segundo Machado e Miranda (2014) a construção da autonomia nas escolas depende da compreensão de que um modo de gestão integrada deve estar apoiado na noção de gestão estratégica e participativa. Para os autores, com base nas exigências advindas de um modo de gestão integrada, entende-se que o melhor caminho para essa prática é o da gestão estratégica e participativa.

Ao afirmar que a gestão integrada aplicada à educação pressupõe as relações de interdependência existentes entre o nível macro - secretarias e órgãos executores - e o micro - escolas - do sistema educacional, isso significa dizer que as decisões tomadas no nível macro, seja na forma de políticas ou de regulamentações, devem considerar a capacidade das escolas de as operacionalizarem, adequando-as à realidade em que estão inseridas.

Nesta perspectiva, os autores afirmam que o grau de participação de indivíduos, de grupos ou de unidades no processo decisório de uma organização é definido por critérios como competência e distribuição de poder para tal descentralização.

No entanto, a gestão participativa atende às exigências próprias do processo de democratização na educação, ou seja, o princípio da democratização aplicado ao processo de gestão educacional se traduz em participação. Isto reforça o entendimento de que a adoção de um modelo participativo de gestão, no âmbito dos sistemas de educação, traz implícita a discussão sobre o grau de descentralização, a construção da autonomia e a responsabilização das instâncias constitutivas desses sistemas, inclusive as escolas, tendo em vista que possibilidade de participação nos processos decisórios depende do grau de descentralização do poder de decisão nos sistemas educacionais e da autonomia que as unidades escolares possuem para agirem de maneira proativa. Porém, a autonomia nos processos decisórios pressupõe responsabilidade sobre os seus resultados (Machado; Miranda, 2014).

\section{Metodologia}

Para uma melhor análise das questões citadas o trabalho foi fundamentado em uma pesquisa qualitativa de cunho bibliográfico, análise documental e estudo de caso, utilizando para coleta de dados o método de entrevista semiestruturada, em uma escola pública da cidade de Belo Horizonte/MG.

Propusemos adotar como procedimento metodológico a pesquisa qualitativa de caráter descritiva, por ser entendida como procedimento e instrumento de coleta de dados que permite a sistematização dos estudos bibliográficos realizados, no sentido de conhecer os caminhos que pontuam a discussão do tema proposto (Alves-Mazzotti, Gewandsznajder, 1998). A presença dessas condições aproxima o interesse em adotar a pesquisa documental por vale-se de materiais que ainda não receberam um tratamento analítico visto que suas fontes são muito diversificadas e dispersas ou que ainda podem ser reelaboradas de acordo com os objetivos da pesquisa como afirma Gil (2002). Além 
disso, permitirá levantar informações sobre os princípios da gestão democrática e da autonomia da escola a partir de documentos oficiais como a Constituição Federal de 1988 e Lei de Diretrizes e Bases da Educação Nacional de 1996, a fim de compreender o sentido destas temáticas no âmbito escolar.

Na pesquisa de campo destacou-se a organização do trabalho do gestor escolar em uma Escola pública estadual de Educação Básica localizada na região de Belo Horizonte no Estado de Minas Gerais. O trabalho envolveu a revisão de literatura abordando os temas autonomia da escola, gestão democrática e a práticas de gestão, em diálogo com o levantamento de informações obtidas nos documentos oficiais, assim como a realização de entrevista, procurando identificar aos temas emergentes no sentido de mapear as diferentes formas de atuação do gestor escolar e as formas de ação no contexto de sua realidade, permitindo, desse modo, identificar sua opinião sobre a autonomia da escola na perspectiva da gestão democrática e suas implicações em sua gestão. $O$ roteiro de entrevista foi o seguinte: nas deliberações acerca de questões financeiras, pedagógicas e administrativa, qual o lócus privilegiado dentre elas que se efetivam na prática e permite a ocorrência da autonomia escolar? Até que ponto a autonomia da escola vem contribuindo para o enfrentamento das questões concretas relativas à gestão de sua escola ultrapassando 0 discurso generalizante que termina por constituir contemplativamente na construção da gestão democrática? Elas acontecem simultaneamente ou há alguma deliberação que sobressai as demais? Há ainda presença de critérios burocráticos para manutenção ou implantação ações inovadoras na escola tendo como eixo estruturante o PPP? Qual seria a proposta educativa adequada para o fortalecimento da autonomia escolar e que possa oferecer sustentação à gestão democrática? Há presença e participação no trabalho coletivo de professores?

\section{Atribuições do gestor escolar e análise dos dados coletados}

As reuniões e conversas realizadas com o gestor escolar apresentam uma zona de fronteira entre teoria e prática em face às especificidades da instituição escolar e seu processo educativo na gestão de sua escola. Estes indicadores e as causas que thes atribuem para construir ações autônomas e de gestão democrática foram obtidos através da realização de reuniões e conversa informal com o gestor escolar bem como coleta de dados a utilização de entrevista.

Solicitou-se ao gestor escolar que se manifestasse sobre a gestão democrática da sua escola. Observamos em sua manifestação que a gestão democrática tem sido uma reinvindicação da categoria dos professores, por acreditar que a participação dos profissionais na escola, da família e da comunidade em geral estivessem relacionados aos assuntos e problemas de gerenciamento da escola. Diante desta constatação, o gestor escolar enfatizou que a construção da gestão democrática acontece bastante limitada, principalmente, pelas leis que começa a engessar o trabalho da escola, impedindo que ela se torne efetiva no contexto escolar.

Solicitamos ao gestor escolar para comentar sobre as questões financeiras, pedagógicas e administrativas de sua gestão, de modo que seria necessário assegurar a efetiva participação da equipe escolar. Na perspectiva do gestor escolar a gestão financeira controla e evita abusos. No entanto, os recursos financeiros limitam a autonomia do gestor. A burocracia leva a adotar uma postura inadequada aos problemas escolares, uma vez que estaria comprometendo as reais necessidades da escola. 
Em relação ao pedagógico o gestor expressou que com o apoio da Secretaria de Educação vem desenvolvendo o trabalho coletivo em torno das proposições curriculares, do acompanhamento do método de ensino dos professores em sala de aula e da vida escolar dos alunos e das turmas em cada semestre. O principal objetivo é garantir a participação de todos nos assuntos relacionados às questões pedagógicas da escola, visando aos bons resultados da escola. No administrativo a escola segue o estatuto do funcionário público municipal e toda a legislação que a prefeitura incorpora sobre os assuntos educacionais, tanto da administração direta e indireta. Partindo desta afirmação do gestor escolar, este reconhece o cumprimento de normas para tomar as decisões necessárias e ter um parâmetro para não incorrer em práticas antiéticas.

Questionou-se, também, de que maneira o gestor entende a tomada de decisões enquanto profissional atuante na escola. A falta de cultura da participação dos atores sociais tem sido a dificuldade apontada pelo gestor, tendo em vista que, as vezes, percebemos que na sua gestão, tem sido frequente a tomada de decisões coletivamente. Nessa perspectiva, o gestor enfatizou que todos os assuntos escolares são compartilhados e avaliados por todos os professores, vice-diretor, coordenadores de modo a contribuir para melhoria do desempenho da escola.

Outro ponto a destacar refere-se às reflexões sobre a explicação da sua autonomia na gestão da escola. Pode-se perceber em seus relatos que a autonomia ainda é bastante limitada pela legislação, pelo Caixa Escolar administrado pela prefeitura local. Neste respaldo, foi possível perceber que os recursos financeiros se constituem no grande desafio da escola. Outro destaque do gestor escolar no que diz respeito a autonomia pedagógica, a escola leva em consideração a tomada de decisão junto ao Colegiado Escolar, às assembleias escolares e aos representantes de pais e professores sobre as questões relacionadas a gestão da escola.

Indagou-se até que ponto a autonomia da escola vem contribuindo para o enfrentamento das questões concretas relativas à gestão de sua escola. Percebemos ao longo de sua manifestação que a autonomia é bem diferente nos dias de hoje. Por se tratar de uma limitação no fazer pedagógico da escola, a autonomia relativa tem consequências adversas ao desejo da comunidade escolar. Há reivindicações por parte de pais, colegiado e de professores, mas nem sempre são possíveis de serem atendidas e também, algumas propostas pedagógicas nem sempre são corretas em consonância com os objetivos da escola. E para não ferir a lei, o gestor afirma que busca trabalhar dentro do que é proposto pelo governo e da prefeitura local. No entanto, ainda há muitas formalidades e documentos padronizados que regulariza e limita a atuação do gestor. Assim, ele indica a necessidade de incluir a gestão de verbas que não estão colocadas ou descritas na lei.

Um argumento importante para a delimitação deste debate é se as questões financeiras, pedagógicas e administrativas acontecem simultaneamente ou há alguma deliberação que sobressai as demais. De acordo com o gestor escolar, as atividades ocorrem simultaneamente em sua direção. Para ele não há como desvincular as questões financeira do pedagógico e do administrativo. Mas reconhece o pedagógico com a identidade da escola. A possibilidade de dialogar com professores, trabalhar com programas educativos da prefeitura local e elaboração conjunta do PPP são alguns 
exemplos da importância de organizar o trabalho pedagógico no interior da escola. No entanto, para qualquer tomada de decisão na escola está atrelado aos recursos financeiros - o caixa escolar - para que possam articular práticas pedagógicas e administrativas com o planejamento escolar.

As reflexões para que o gestor comentasse sobre a presença de critérios burocráticos para manutenção ou implantação ações inovadoras na escola, tendo como eixo estruturante o PPP, também, se destaca, ao perceber que os cortes no financiamento da educação no País tem gerado um descontentamento da equipe escolar. Mais uma vez, a limitação das verbas públicas foi apontada pelo gestor. A burocracia e a busca por liberação de recursos do caixa escolar é outro ponto de destaque. Esta insegurança econômica tem impedido a realização de muitos projetos na escola tais como exemplo a reforma da quadra esportiva, como ele mesmo cita. E reconhece que qualquer atitude mal tomada ou contrária à liberação de verbas que não sejam condizentes com autorização das entidades locais responsáveis pelo financiamento pode acarretar em desvio de verba pública.

Foi-Ihe solicitado apresentar propostas educativas adequadas utilizadas na gestão de sua escola para o fortalecimento da autonomia escolar e que poderia oferecer sustentação à gestão democrática. A manifestação a seguir resume bem o argumento do gestor: "A direção, ela não é mais aquela coisa que você chega e manifestação, olha você tem que fazer isso, não é isso e quando foi feita a proposta da gestão democrática, era exatamente para as pessoas da escola se sentirem participantes daquilo que estava acontecendo no seu espaço" (G-1). A partir desta afirmação é compreensível como o entrevistado apresenta elementos para assegurar a construção da gestão democrática da escola. Buscar o envolvimento e apoio dos pais nos assuntos da escola; ouvir o pessoal do administrativo e também de professores, cantineiras, auxiliares de serviços e bibliotecária.

Ao referir a importância da interação e participação de todos, o gestor escolar reconhece a busca constante para a melhoria da qualidade em educação, ou seja, a escola está aberta ao diálogo para todos que atuam no seu interior também para aqueles que estão no seu entorno. Além de dar-lhes sentido em todas as instâncias do processo político, é perceptível nas observações realizadas pelo dirigente que a escola deve estar sempre aberta as parcerias. Considera que ampliar o espaço escolar a fim de torná-la democrática requer resgatar constantemente promover reuniões pedagógicas para uma aproximação mais consistentes entre os membros da equipe escolar. Ressalta, também, que não faz sentido um projeto político-pedagógico sem a colaboração do pouco envolvimento e compromisso com a função social da escola.

Por fim apresentamos para a discussão de que maneira a presença e participação do trabalho coletivo de professores ocorre em sua gestão e para elaboração de ações para o PPP. Foi relatado que a identidade da escola tem sido o trabalho coletivo na elaboração do PPP. O gestor escolar ressalta que a escola vem renovando o quadro de profissionais da educação e que muitos dos seus membros têm trazido uma cultura totalmente diferente da escola em que exerciam alguma atividade. Desse modo, tem sido muito difícil estabelecer relações no âmbito da coletividade. Isto não quer dizer, que a 
escola seja autoritária e tradicional. Como diretor de escola, ele afirma que seu papel é a busca constante de manter o grupo unido em torno de um trabalho sério e coeso na tentativa de democratizar as tomadas de decisões e fazer com que cada membro da escola seja partícipe nos assuntos da escola.

Em linhas gerais, a investigação realizada na escola tem evidenciado que a gestão democrática acontece ainda de forma bastante limitada. $O$ gestor escolar assume compromissos, assume metas impostas pela legislação brasileira e que vem orientando todo o processo educativo dentro da gestão. Isto reforça a ideia de que a autonomia escolar é parcial e limitada no sentido de engessar o trabalho escolar e isto leva a gestão democrática efetivamente não acontecer. Percebemos, também, que a tomada da decisão no espaço escolar tem sido complexo, apesar o gestor escolar poder contar com apoio da supervisão e comunidade escolar em geral.

A presença de critérios burocráticos para manutenção ou implantação ações inovadoras na escola ainda tem sido o grande gargalo da gestão democrática da escola, principalmente no que diz respeito às questões financeiras, pedagógicas e administrativas. Pensando sobre se alguma deliberação desta questão sobressai sobre as demais, vimos que o financeiro, devido à questão da limitação das verbas, realmente torna-se muito burocrático e que acaba limitando o fazer pedagógico e administrativo da escola. Constatamos a necessidade de fortalecimento da autonomia da escola por intermédio do envolvimento de pais e professores na tomada de decisão nos assuntos escolares, isto leva a afirmamos a necessidade do gestor não se sentir isolado dos demais sujeitos participantes da escola.

\section{Considerações finais}

A pesquisa buscou investigar a autonomia escolar na perspectiva da gestão democrática, cujos enunciados vem estatuindo um novo pensar e agir no âmbito escolar. Há um forte consenso que existe um amplo território a ser investigado quanto à necessidade de mudanças significativas na escola sob o prisma da autonomia e da democratização da escola. Nesse sentido, as questões referentes à gestão da escola pública no processo de implementação das políticas educacionais requer a observação da interpretação que o diretor faz sobre os fatos, planos e propostas expostos pelos atores escolares, e como ele conduz a gestão da sua equipe.

Fortalecer o compromisso do gestor escolar e de professores para a construção da gestão democrática e para autonomia nuclear nas tomadas de decisões da escola continua a ser um bom caminho a percorrer.

A gestão democrática como instrumento de luta contra a gestão burocrática da escola e que ainda se reproduz na escola vem dando ênfase na necessidade de repensar as propostas educativas no seio da gestão escolar. Defendemos caminhos alternativos a organização do trabalho pedagógico da escola contemplando a plena decisão do gestor escolar às questões administrativa, pedagógica e operacional em sua gestão, de modo a ampliar o mínimo necessário no que tange aos recursos necessários ao seu bom desenvolvimento. 
É preciso problematizar as relações interpessoais e de praticidade que ocorrem na escola. Acreditamos ser necessário que seja acompanhada em seu desenvolvimento o envolvimento da comunidade escolar aos assuntos da escola. Sabemos que não é tarefa fácil, mas o gestor escolar tem buscado incessantemente proporcionar uma escola democrática como o mínimo de autonomia a que lhe é posto. A partir da perspectiva deste estudo, podemos concluir que boa parte das questões a serem enfrentadas pelo gestor escolar, tem origem mais profunda na própria autonomia escolar que é limitada, compartilhando com o sujeito de nossa investigação. Devido à multiplicidade de tarefas a serem realizadas em sua gestão acaba restringindo a construção de uma gestão mais democrática na escola. Neste sentido, é preciso reforçar estudos e pesquisas realizadas a partir de experiências do gestor escolar no qual dificuldades expostas e avanços compartilhados possam direcionar e garantir a tão sonhada gestão democrática da escola.

\section{Referências}

ALVES-MAZZOTTI, Judith; GEWANDSZNADJER, Fernando. O planejamento de pesquisas qualitativas. In: ALVES-MAZZOTTI, Judith; GEWANDSZNADJER, Fernando. $O$ método nas ciências naturais e sociais: pesquisa quantitativa e qualitativa. São Paulo: Pioneira, 1998, p. 147-178.

BRASIL. Conselhos escolares: uma estratégia de gestão democrática da educação pública. Brasília: MEC, 2014.

BRASIL. Lei de Diretrizes e Base da Educação Nacional, de 20 de dezembro de 1996. Disponível em http://www.planalto.gov.br/ccivil 03/Leis/L9394.htm. Acesso em 7 abr. 2016.

BRASIL. Conselhos escolares: uma estratégia de gestão democrática da educação pública. Brasília: MEC, 2004. Disponível em http://portal.mec.gov.br/seb/arquivos/pdf/Consescol/ce gen.pdf. Acesso em 1ํabr. 2016.

CASTRO, Alda Maria Duarte Araújo. A qualidade da educação básica e a gestão da escola. In: FRANÇA, Magna; BEZERRA, Maura Costa (orgs.). Política educacional: gestão e qualidade do ensino. Brasília: Líber Livro, 2009, p. 21-44.

CURY, Carlos Roberto Junior. Gestão democrática da educação: exigências e desafios. Revista Brasileira de política e Administração da Educação, São Bernardo do Campo, v. 18, n. 2, 2002, p. 163-174.

DALBERIO, Maria Célia Borges. Neoliberalismo, políticas educacionais e a gestão democrática na escola de qualidade. São Paulo: Paulus, 2009.

GIL, Antônio Carlos. Como elaborar projetos de pesquisa. São Paulo: Atlas, 2002.

LIBÂNEO, José Carlos; OLIVEIRA, João Ferreira; TOSCHI, Mirza Seabra. Educação escolar: políticas, estruturas e organização. São Paulo: Cortez, 2010.

LÜCK, Heloisa. Perspectivas da gestão escolar e implicações quanto à formação de seus gestores. Em Aberto, Brasília. v. 17, n. 72, 2000, p. 1-19.

MACHADO, Márcia Cristina da Silva. MIRANDA, Josélia Barbosa. Autonomia e Responsabilização: um desafio para a gestão escolar. Revista Pesquisa e Debate em Educação, v. 2, n. 2, 2012, p. 8-22.

MINAYO, Maria Cecília (org.). Pesquisa social: teoria, método e criatividade. Petrópolis: Vozes, 1994. 
PARO, Vitor Henrique. Gestão democrática da escola pública. São Paulo: Ática, 2001.

PARO, Vitor Henrique. Diretor escolar: educador ou gerente? São Paulo: Cortez, 2015.

SEVERINO, Antônio Joaquim. Metodologia do trabalho científico. São Paulo: Cortez, 2007.

WITTMANN, Lauro Carlos. Autonomia da escola e democratização de sua gestão: novas demandas para o gestor. Em aberto, Brasília, v. 17, n. 72, 2000, p. 88-96.

José Márcio Silva Barbosa é e estudante no curso de doutorado em Educação pela Universidade Federal de Minas Gerais.

Endereço: Rua dos Guaranis 564/905 - 30120-040 - Belo Horizonte - MG - Brasil.

Orcid: https://orcid.org/0000-0003-4582-5009.

E-mail: jmarciosb@yahoo.com.br.

Fernando Alvarenga Cardoso Coelho é estudante no curso de Pedagogia da Universidade do Estado de Minas Gerais.

Endereço: Rua Heitor Sócrates Cardoso, 243 - 31560-320 - Belo Horizonte - MG Brasil.

Orcid: https://orcid.org/0000-0003-4306-1172.

E-mail: fernando-alvarenga@live.com.

Recebido em 19 de julho de 2018.

Aceito em 27 de outubro de 2018.

(c) (i) 